NBS

UBLICATIONS

\author{
JBSIR 81-2415
}

\title{
Furnace Pressure Probe Investigation
}

U.S. DEPARTMENT OF COMMERCE

National Bureau of Standards

National Engineering Laboratory

Center for Fire Research

Washington, DC 20234

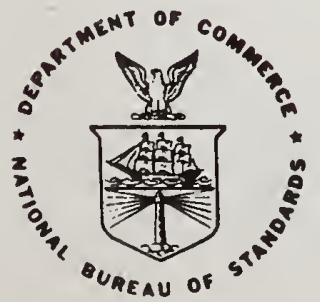



NBSIR $81-2415$

$\cdots$

FURNACE PRESSURE PROBE INVESTIGATION

James S. Steel

U.S. DEPARTMENT OF COMMERCE National Bureau of Standards National Engineering Laboratory Center for Fire Research

Washington, DC 20234 


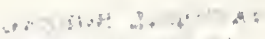

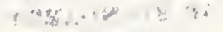

पर 
CONTENTS

Page

LIST OF TABLES . . . . . . . . . . . . . . . . . . . iv

LIST OF FIGURES . . . . . . . . . . . . . . . . . . . iv

Abstract . . . . . . . . . . . . . . . . . 1

1. INTRODUCTION . . . . . . . . . . . . . . 1

2. DESCRIPTION OF PROBES TESTED . . . . . . . . . . 4

3. DEMONSTRATION OF VELOCITY SENSITIVITY . . . . . . . . 6

4. RESULTS OF THE FIRST DEMONSTRATION . . . . . . . . . 8

5. DEMONSTRATION OF PRESSURE PROBE PERFORMANCE

IN A FURNACE ENVIRONMENT . . . . . . . . . . . . 10

6. RESULTS OF THE SECOND DEMONSTRATION . . . . . . . . . 12

7. CONCLUSIONS . . . . . . . . . . . . . . 13

8. RECOMMENDATIONS . . . . . . . . . . . . 14

9. REFERENCES. . . . . . . . . . . . . . . 15 
Figure 1. Probes . . . . . . . . . . . . . . 17

Figure 2A. ISO Sketch . . . . . . . . . . . . . . 18

Figure 2B. ISO Drawing . . . . . . . . . . . . . 19

Figure 3. Photograph of Apparatus . . . . . . . . . . 20

Figure 4. Probe and Fan Angles . . . . . . . . . . . 21

Figure 5. "Circuit" Diagram of Pressure Switch . . . . . . . 22

Figure 6. Record from a Furnace Experiment . . . . . . . . 23

Figure 7. Probe Response Relative to Group Average . . . . . . 24

LIST OF TABLES

Page

Table 1. Pressure Developed by Probes . . . . . . . . . 16 


\title{
FURNACE PRESSURE PROBE INVESTIGATION
}

\section{James S. Steel}

\begin{abstract}
Several pressure probes of types used in fire endurance furnaces were tested at room temperature and compared in a furnace. None of the probes were capable of reliable static pressure measurement in a furnace environment. It is suggested that the total pressure normal to the specimen surface be measured instead of static pressure and that the most accurate probe is a small flush hole in the specimen.
\end{abstract}

\section{INTRODUCTION}

Many probes have been designed to measure the static pressure in fire endurance furnaces. The original object of this investigation was to determine which probe design was most accurate, i.e., which probe generates the correct value of static pressure in a furnace environment. All the probes tested represent designs which are actually in use. 
Furnace pressure is known to be a significant parameter in the fire endurance rating obtained in tests of doors, walls, and floor assemblies since one criterion of integrity in such tests is the passage of flames or gases hot enough to ignite cotton $[1,2,3] .1$ The specification of a positive furnace pressure is consistent with observations and measurements of pressures developed within burning rooms and compartments [4].

ISO Standard 834 "Fire Resistance Tests - Elements of Building Construction" [2] states that the furnace static pressure shall be measured and controlled so that a positive pressure is maintained over the upper two-thirds of the door. This report discusses the problem of measuring the pressure to which a fire test specimen is exposed and summarizes the results of experiments conducted to compare pressure probes which are sometimes used to measure small pressure differences in a furnace environment.

McCaffrey and Rockett [5] used tubes flush with a wall for pressure measurements in their investigations of enclosure fires.

Owen and Parkhurst [6] give a comprehensive description of the problems of measuring static and velocity pressures. They state ". . static tubes are much more sensitive to angular deviations than pitot tubes." Our data strongly confirm this statement.

\footnotetext{
${ }^{1}$ Numbers in brackets refer to literature references listed at the end of this paper.
} 
In fluid mechanics, distinction is made between total pressure, static pressure, and velocity pressure. Historically, static pressure has been the parameter selected for measurement in fire endurance furnaces. This was a questionable selection since specimen penetration is a function of the sum of the static pressure and the component of velocity pressure normal to the specimen surface rather than merely the static component. This choice of measurement parameter led to the development of several "static" pressure probes, some of which were tested here. All of these probes can be expected to develop the correct static pressure when the velocity component of pressure is neglibible. When the velocity component is significant, then probe responses may differ.

It is important to keep in mind that while the probes were designed to measure static pressure, the actual parameter to which the specimen responds is the sum of the pressures perpendicular to its surface. This pressure is easy to measure; the appropriate probe is simply a small hole in the specimen surface that can be connected to a transducer.

The pressure can be expected to vary over the surface of a specimen due to motion of gas within the furnace. 


\section{DESCRIPTION OF PROBES TESTED}

The eight probes tested in the first experiment were selected as being representative of probes actually used in fire endurance testing. Drawing of the probes are given as figure 1 .

ISO Standard 3008 [3] includes a sketch (see figure 2A) of a probe for monitoring furnace pressure. A scale drawing of the probe design is given as figure 2B. Dimensions not given in the sketch were arbitrarily selected; most notable of these are the bend radius and the length of vertical tubing after the bend. In any event, construction of this probe would be complicated by the necessity of bending large thick walled steel tubing on a small radius. The probe actually constructed (probe 1 in figure 1) was much easier to build, and probably responds to air currents in much the same way as would a standard ISO probe. In fact, since the bend radius and vertical height were not specified in the ISO standard, an argument could be made that probe 1 is essentially an Iso probe.

Probe 2 is a tee made from $19 \mathrm{~mm}$ outside diameter tubing. It is identical to probe 1 except no baffle is included.

Probe 3 is a $25 \mathrm{~mm}$ diameter stainless steel disc, $6 \mathrm{~mm}$ thick. The sensing hole is $3 \mathrm{~mm}$ in diameter and is drilled through the center of the disc. The probe is referred to as a "lollipop." 
Probe 4 is identical to probe 3 , except the edges of the disc are rounded. This probe is a classic static pressure probe in fluid mechanics and must be aligned so that the sides of the disc are parallel to the flow. This probe is called a "round-edged lollipop."

Probes 5 and 6 are plain open tubes, of 4.75 and $9.50 \mathrm{~mm}$ diameter, respectively.

Probe 7 is a closed-end tube, $9.5 \mathrm{~mm}$ diameter, with 4 cross drilled holes, each $1 \mathrm{~mm}$ diameter. This probe resembles the static pressure measuring component of probes used in many commercial versions of combination pitot and static tubes. This probe is called a "perforated tube."

Probe 8 was constructed from a cast iron pipe cap turned to a spherical shape. Five sensing holes, each $1 \mathrm{~mm}$ in diameter, were drilled in the sphere in mutually orthogonal directions. The original probe was used in the first demonstration. A second similar probe constructed of stainless steel was used in the second demonstration furnace (furnace test) because the epoxy used in mounting the first probe made it unsuitable for high temperature use. This probe is called the "tea ball." 


\section{DEMONSTRATION OF VELOCITY SENSITIVITY}

There are three types of errors which can be attributed to pressure probes. These are: (a) inaccurate transmission of static pressure, (b) pressure head due to height and density difference (the chimney effect), and (c) dynamic response of the probe.

Errors in pressure transmission can be caused by factors such as clogged or restricted probe orifices, foreign substances in pressure lines, and leaks. These reflect poor experimental technique, not faults in probe design.

The chimney effect is directly proportional to the height of the "chimney" formed by the vertical extension of probe tubing inside the furnace. In all of the probes tested here, this height was zero and the chimney effect (pressure head) was not investigated. The chimney effect can be significant in some cases, e.g., a pressure probe mounted vertically in a floor assembly.

The ISO standard 3008 specifies a probe with a non-zero chimney height (figures $2 \mathrm{~A}$ and $\mathrm{B}$ ). This height is not given but could typically be $8 \mathrm{~cm}$ or less. Calculation shows the chimney effect error to be about $-1.2 \mathrm{~Pa}$ for a furnace temperature of $700^{\circ} \mathrm{C}$ and a $8 \mathrm{~cm}$ chimney. 
The major potential source of error is velocity sensitivity. While the absolute sensitivity of a probe to velocity will vary with gas density, which is inversely proportional to gas temperature, the relative sensitivity can be expected to remain unaltered.

The experimental method chosen was to use a stream of room temperature air directed toward the probe at various angles. The pressure developed by the probe in moving air was measured. The number of readings required was considerably reduced by symmetry considerations.

By this method, the additional uncertainties of operating in a furnace environment were avoided. The experiment as expected yielded a consistent and valid comparison of behavior of several probe types in substantially identical environments.

The experimental apparatus was quite simple, as can be seen in figure 3. A ducted fan was used to blow air toward the various probes. There were chalk marks on the building floor to aid in placing the fan. The probes were mounted on a vertical plywood board, 1.2 meters square. The pressure developed by the probe was measured using a pressure transducer and carrier demodulator, with a resolution of $0.25 \mathrm{~Pa}$. Air velocity near the probe location was measured using a thermocouple anenomometer. 
Fan angle is the angle between the fan axis and the probe axis; i.e., the fan blows perpendicular to the wall at a fan angle of $0^{\circ}$, and parallel to the wall at a fan angle of $90^{\circ}$.

Probe angle is the angle between a line connecting opposite openings in the probe and the horizontal plane. The concept of probe angle is meaningless for plain tubes and holes, however, for information purposes these data are presented in the $0^{\circ}$ probe angle column in table 1. Figure 4 illustrates the definitions of fan and probe angles.

Probe distance is the distance from the opening(s) in the probe and the wall surface. In the case of the ISO probe, the distance is specified as $25 \mathrm{~mm}$. For the tea ball probe, this distance is taken from the center of the probe.

\section{RESULTS OF THE FIRST DEMONSTRATION}

Results of pressure measurements listed in table 1 show values ranging from -5.0 to $+4.2 \mathrm{~Pa}$. Pressures fluctuated by about \pm 1.5 $\mathrm{Pa}$, and the recorded values represent estimated averages of pressure readings.

The repeatability of test results can be checked at a fan angle of $0^{\circ}$. Since the fan was blowing parallel to the probe axis, the 
pressure should not change when the probe is rotated. These pressures were constant to within $\pm 0.25 \mathrm{~Pa}$, which was the resolution of the pressure sensing apparatus.

At any particular fan angle, pressure differences between probes indicate that at least one of the probes is sensitive to fluid velocity. When the fan angle was $45^{\circ}$ and the probe distance was $50 \mathrm{~mm}$, two probes read $-5.0 \mathrm{~Pa}$ and one probe read $+1.7 \mathrm{~Pa}$.

When fan angle and probe distance are constant, variation of the pressure with probe angle is a strong indicator of velocity sensitivity. The data at a fan angle of $45^{\circ}$ show considerable variation of pressure for probes 1, 2, 3, and 4 and some variation for probe 8 .

Probe 4, the round-edged lollipop, is expected to develop the correct value of static pressure when the air flow is parallel to its sides. This was true when the probe angle was $90^{\circ}$. Since the correct value of static pressure is known, we can determine the performance of the other probes and probe positions by comparison.

The results at a fan angle of $0^{\circ}$ and a probe distance of $25 \mathrm{~mm}$ are not especially enlightening. In this instance, no effect of probe angle was expected and there was little difference in performance among probes. 
At a fan angle of $45^{\circ}$ and a probe distance of $25 \mathrm{~mm}$, variations in probe performance become quite marked. The correct value of static pressure was $+1.2 \mathrm{~Pa}$, as measured by probe 4 with a probe angle of $90^{\circ}$. All the other probes, except probe 1, indicated negative pressures under this condition. But even the probes 1 and 4 do not show this correct value under all conditions. Both of these probes generated negative pressures as the probe angle was changed. Similar but less conspicuous results were obtained with other fan angles and probe distances.

From these results, it is apparent that none of the probes tested can be depended upon to generate the correct value of static pressure when exposed to an air flow from an unknown direction.

\section{DEMONSTRATION OF PRESSURE PROBE PERFORMANCE IN A FURNACE ENVIRONMENT}

A second demonstration of probe performance was conducted in the NBS fire endurance pilot furnace. Five probes were compared in a furnace environment during the fire endurance test of a floor/ ceiling specimen.

The probes tested were: the plain hole $(3.2 \mathrm{~mm} \mathrm{dia})$, the round edge lollipop, the tea ball, the perforated tube, and the Iso probe. A second tea ball was fabricated of stainless steel for this experiment since the epoxy used in fabrication of the first probe was 
unsuitable for furnace use. The ISO probe was modified as described above for ease of construction.

The pressure in the pilot furnace was expected to fluctuate during the test, and it did. Since our purpose was to compare probes, not to measure furnace pressure, the actual value of furnace pressure was of secondary importance. The value sought was the difference in the pressures developed by the various pressure probes in the furnace environment. The apparatus was arranged to produce these results. This was done by connecting one pressure probe to the positive port of a differential pressure transducer and a second pressure probe to the negative port. The transducer output is then proportional to the difference in the pressures developed by the two probes and the effect on the output of furnace static pressure fluctuations is minimized.

In the actual experiment, only one transducer was used. The transducer was connected between successive pairs of probes by a rotary selector valve, the fluid analog of a 2-pole, 12-position electrical switch. This required only one transducer and one chart recorder ( 2 pens) and eliminated errors caused by mismatching transducers and transducer drift. A "circuit" diagram is given as figure 5. In position 0 , the transducer was open to the air, giving a check on the transducer zero output. In position 1, the actual 
total furnace pressure was measured using the flush hole probe. The remaining 10 valve positions compared successive pairs of probes.

The transducer output and a signal proportional to switch position were fed to the strip chart recorder. The valve position was advanced every 30 seconds. An active filter with a 1-second time constant was used to condition the transducer output before recording. Figure 6 is a graph of transducer and switch position output from one of the experiments. In position 1 , the actual furnace pressure is recorded and the fluctuations can be easily seen.

A major limitation of this technique is inadequate knowledge of the flow pattern in the furnace. The differences in probe response can be measured, but since the cause of the variation is not known, then the error function is not well defined.

\section{RESULTS OF THE SECOND DEMONSTRATION}

The data from this demonstration present some problems of intrepretation. Several readings were taken over the course of each test; there is no real standard of performance for comparison and no certainty in the knowledge of air speed and direction. 
Rather than select one probe as a standard, the data are presented as deviations from the group average pressure. Since only deviations were measured, this scheme has the advantage of not requiring a knowledge of the furnace pressure. Examination of the data in figure 6 will show the difficulty of determining the actual pressure in position 1. This "noisy" signal is actually a filtered representation of the furnace pressure. In subsequent positions, this varying pressure was imposed on two probes, and the measurement was made of the differential pressure. The reduction of the noise level results from canceling the effects of furnace pressure variation. This noise canceling effect demonstrates that the "noise" level is very similar in ail of the probes tested. Figure 7 shows the deviation of pressures generated by the probes from the group average.

The two probes with the greatest deviation are the flush tube and the round-edged 1ollipop. Since the direction of air flow is not known, it cannot be assumed that the round-edged lollipop probe measures the correct value of static pressure. What has been shown is that different probes in the same environment may generate different pressures.

\section{CONCLUSIONS}

In the first demonstration, the velocity sensitivities of eight probes were measured at certain flow angles at room temperature. 
These data show that probe design has an appreciable effect on the pressure value obtained when air velocity is a factor. In the second demonstration, five of these probes were compared in a furnace environment. The data show a maximum deviation between probes of about $0.7 \mathrm{~Pa}$.

The demonstrations show that errors can result from probe selection. What was not shown by experiment is which probe design gives the most accurate results. The pressure normal to the specimen is more representative of specimen exposure than static pressure. The simplest and most accurate probe is a small flush hole in the specimen.

\section{RECOMMENDATIONS}

It is recommended that probes of the flush hole type be installed in the specimen mounting frames for fire endurance tests of walls and floors. For tests of windows and doors these probes should be installed in the walls near the specimen. When the fire resistance of the specimen would not be compromised, the probe should be a small tube passing through the specimen, with one end flush with the fire exposed face. 


\section{REFERENCES}

[1] ASTM E 119-79, Standard Methods of Fire Tests of Building Construction and Materials, Part 18, Annual Book of ASTM Standards, 1979.

[2] ISO 834, Fire Resistance Tests - Elements of Building Construction, International Organization for Standards, 1975 plus Amendment 1 (1979).

[3] ISO 3008, Fire-Resistance Tests - Door and Shutter Assemblies, International Organization for Standards, 1976.

[4] Fang, J. B., Static Pressures Produced by Room Fires, Nat. Bur. Std. (U.S.), NBSIR 80-1984 (1980).

[5] McCaffrey, B. J. and Rockett, J. A., Static Pressure Measurements of Enclosure Fires, J. Research of National Bureau of Standards, V. 82, No. 2, 107-117, 1977.

[6] Owen, E. and Parkhurst, R. C., The Measurement of Air Flow, Pergamon Press, New York, 1977, p. 48. 


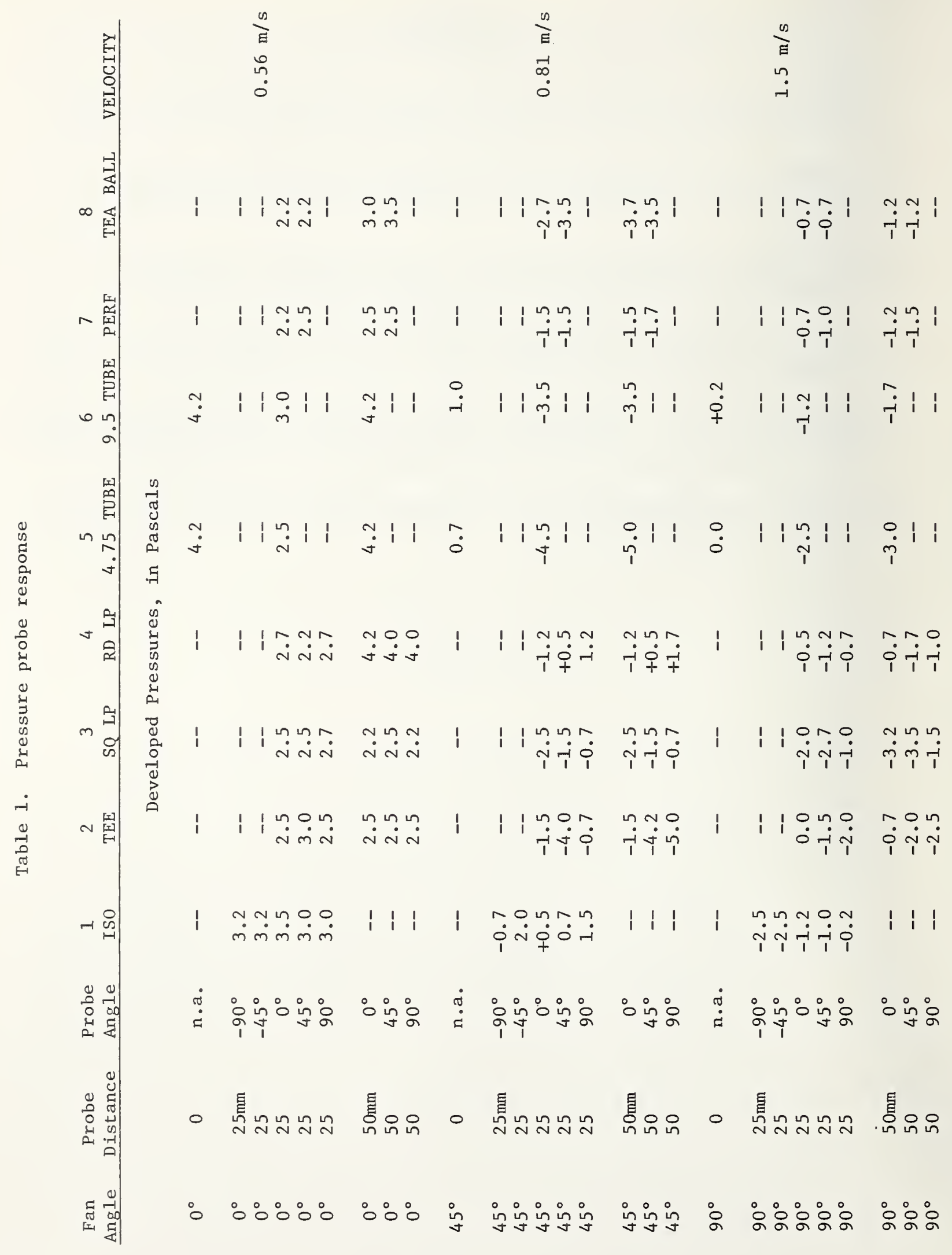



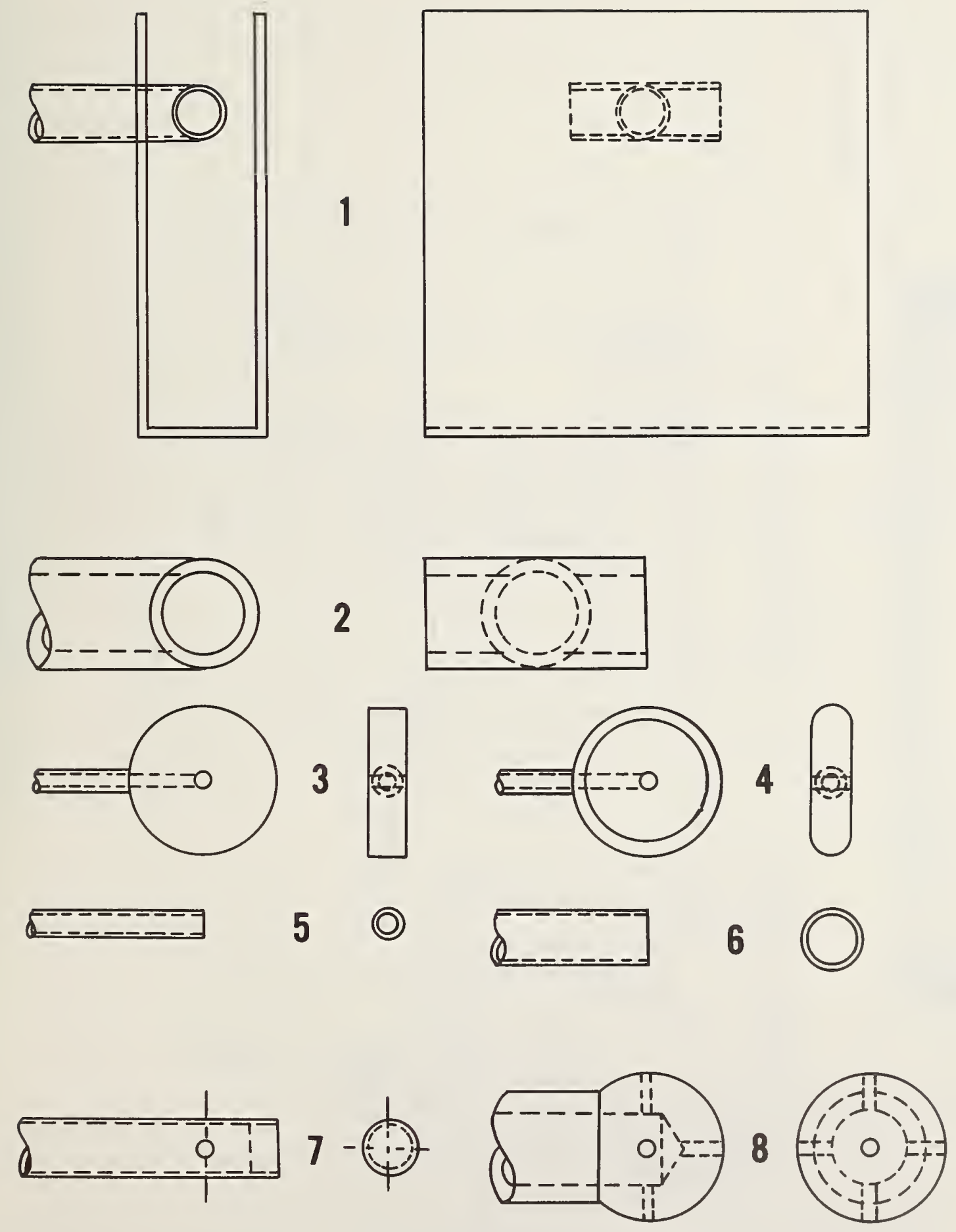

Figure 1. Probes 

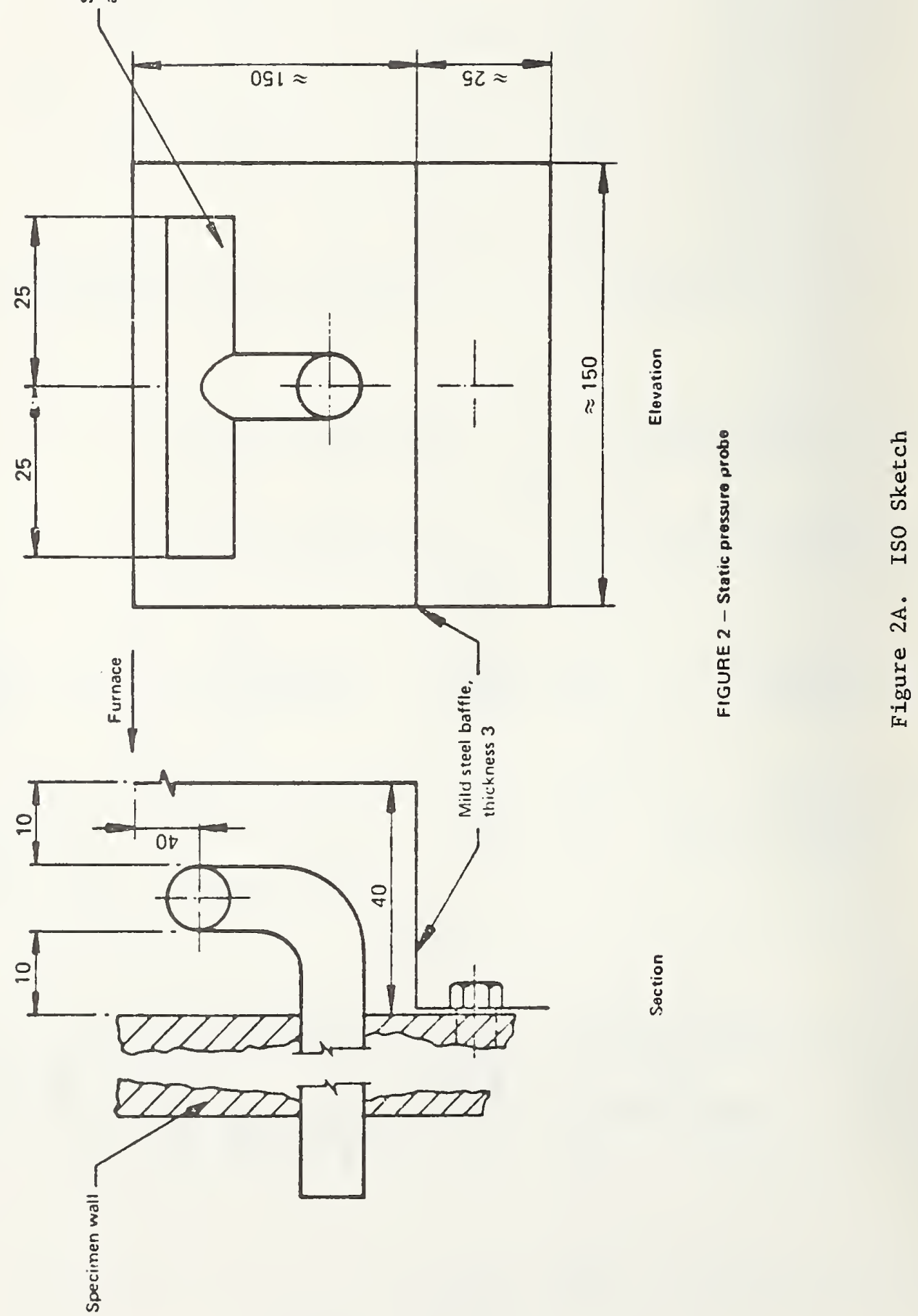

동 


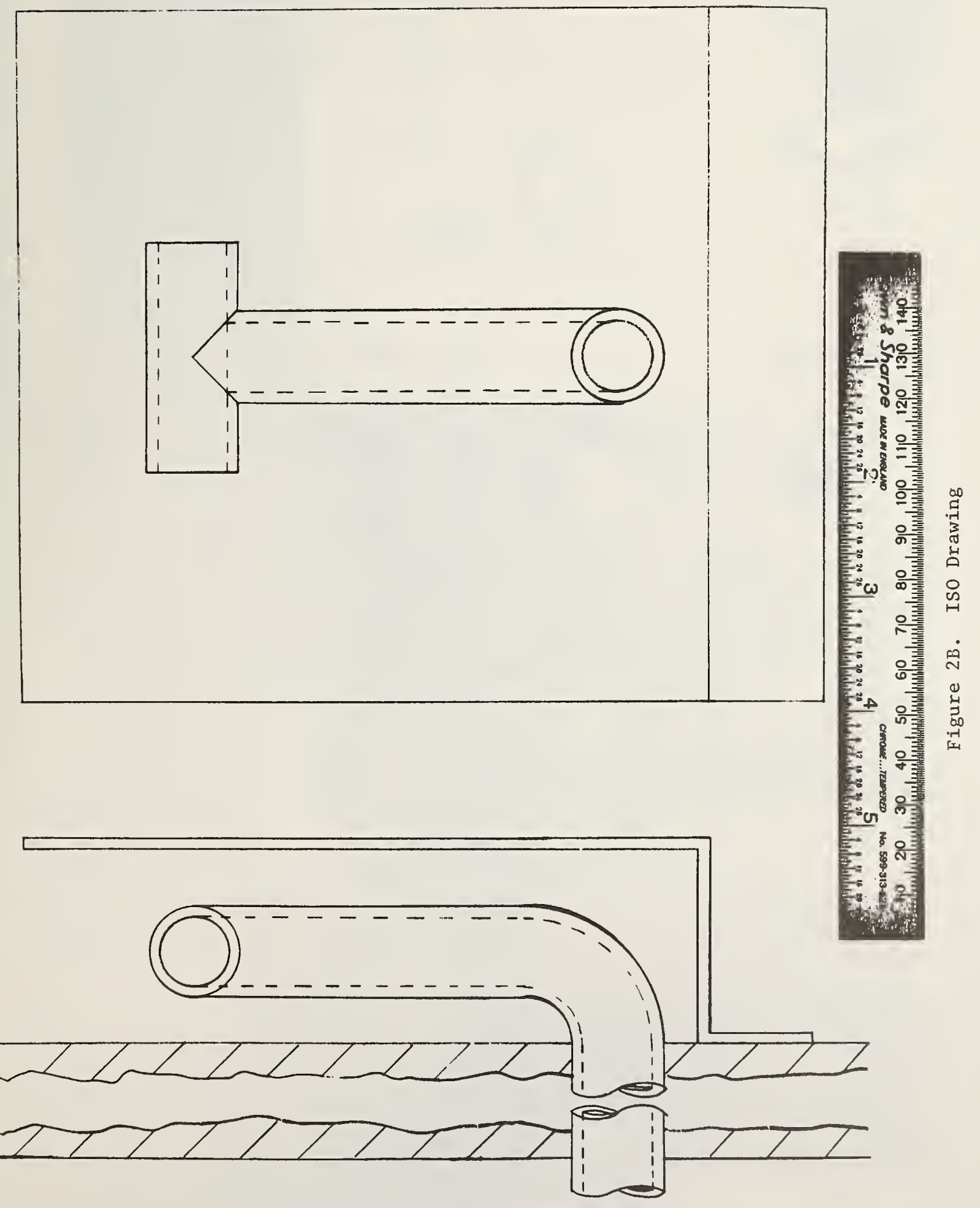



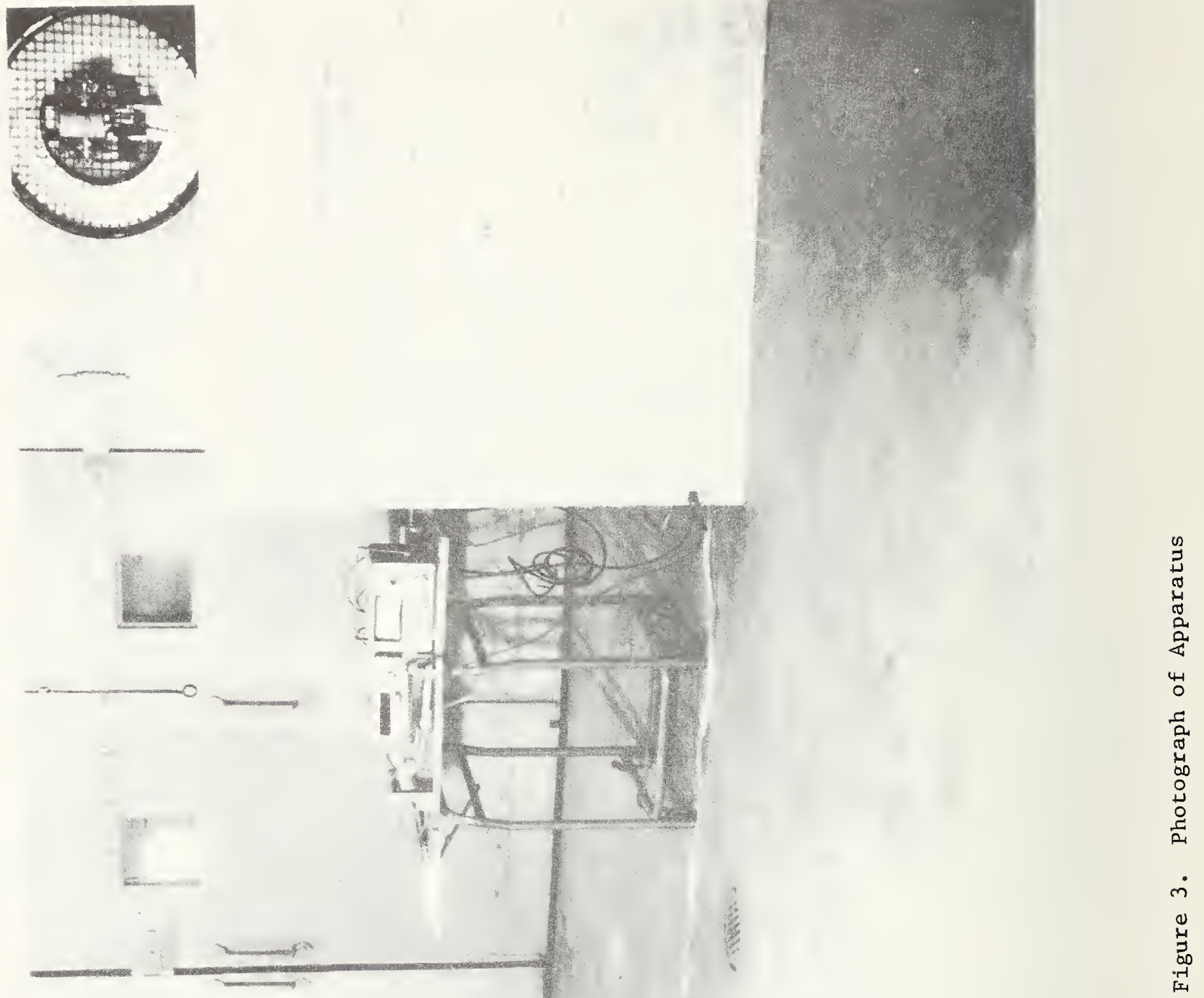


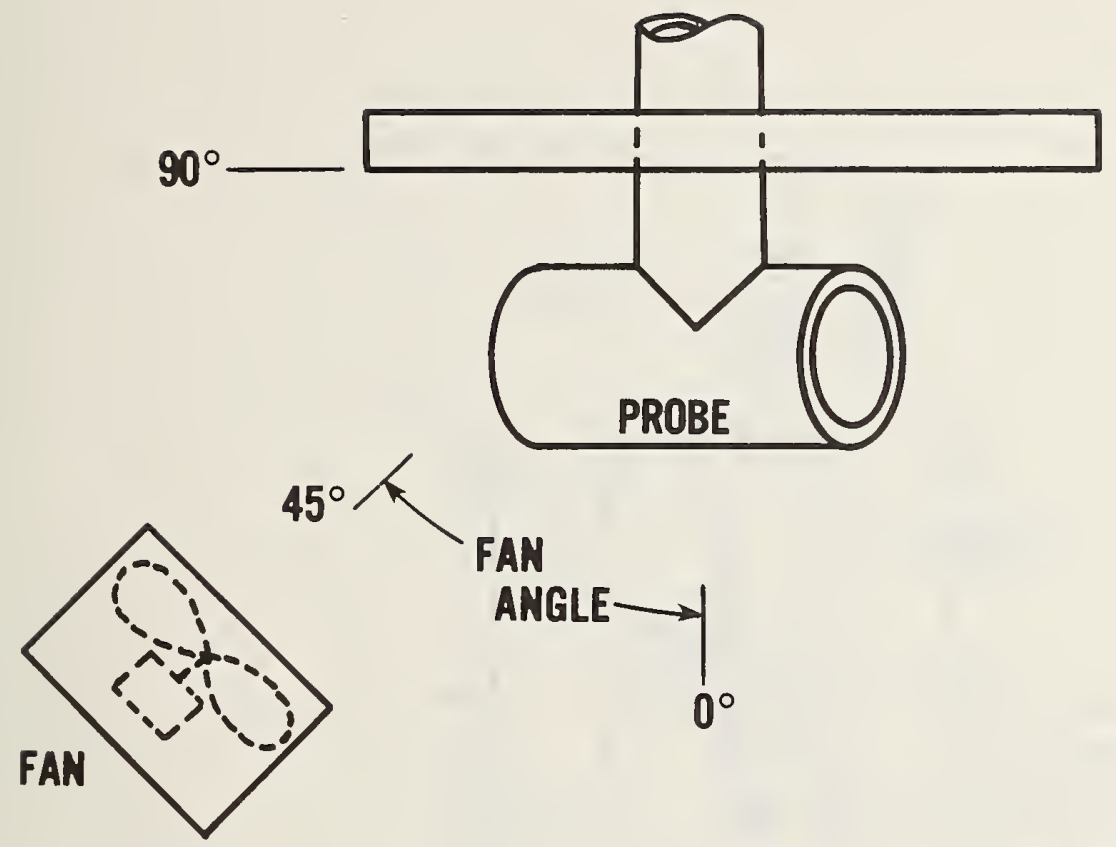

PLAN

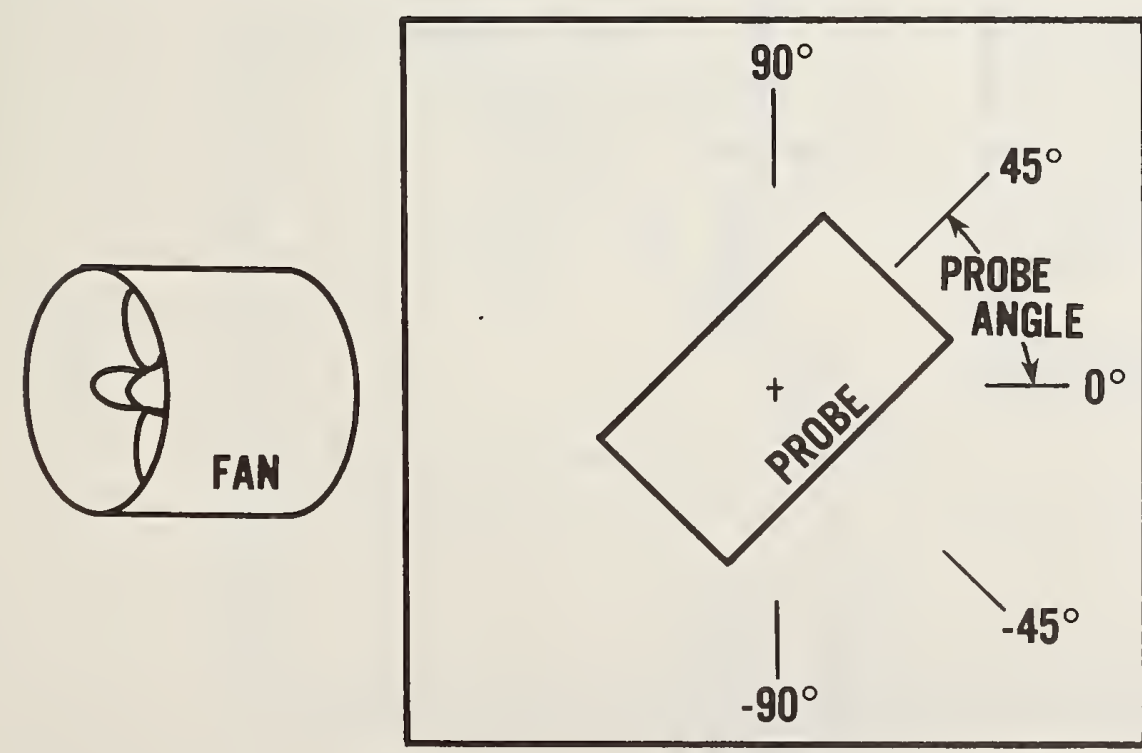

\section{ELEVATION}

Figure 4. Probe and Fan Angles 


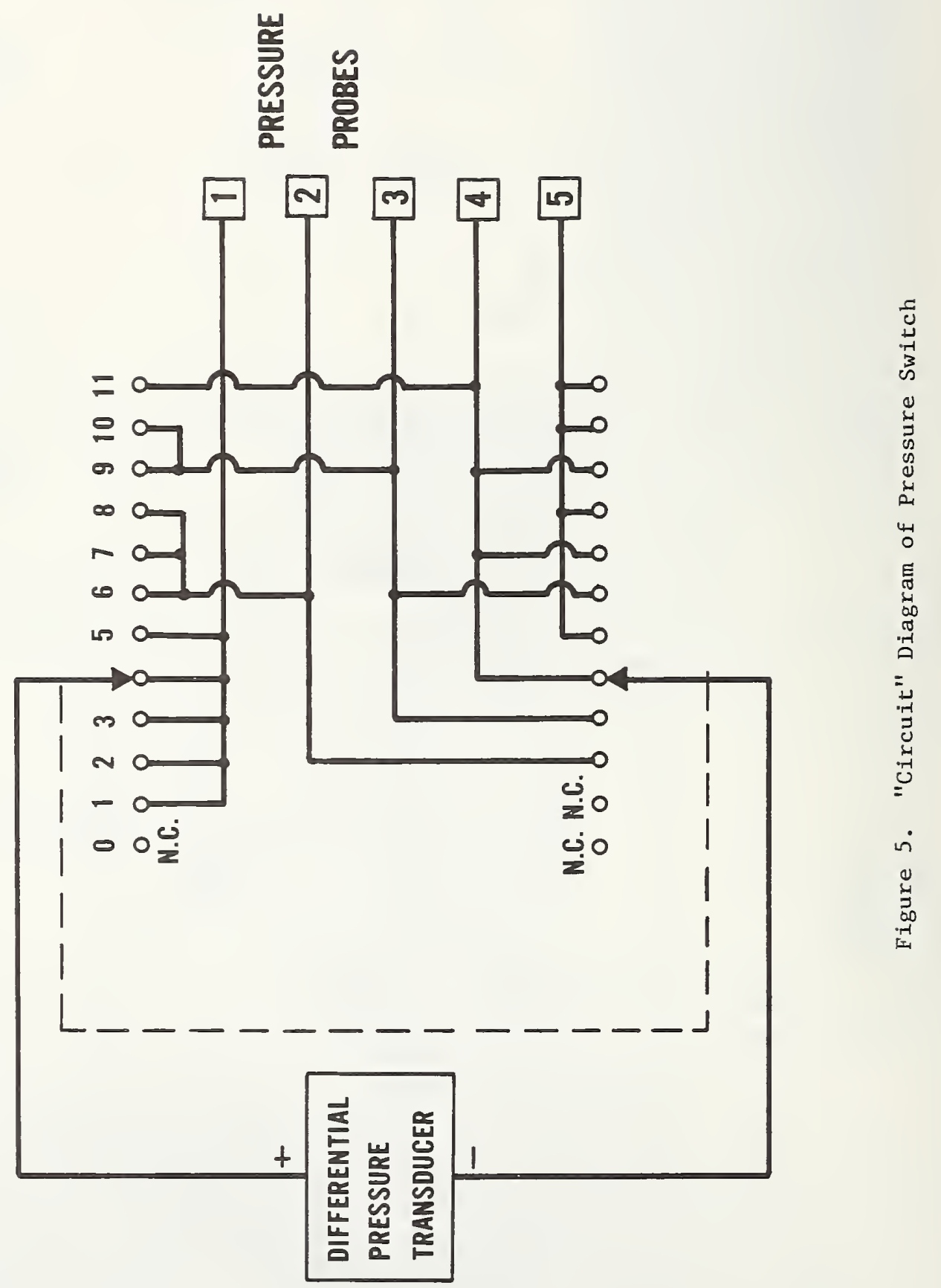




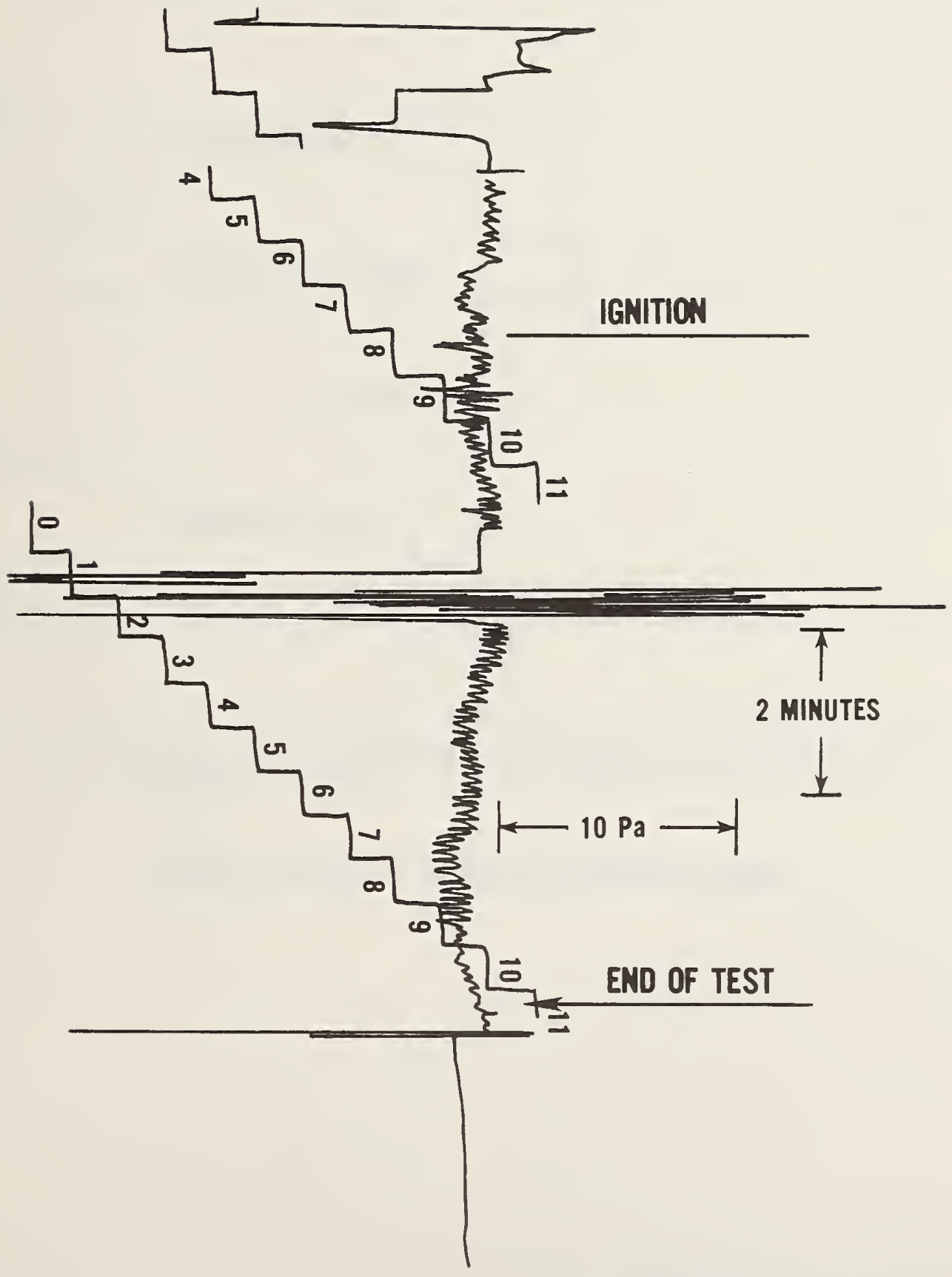

Figure 6. Record from a Furnace Experiment 


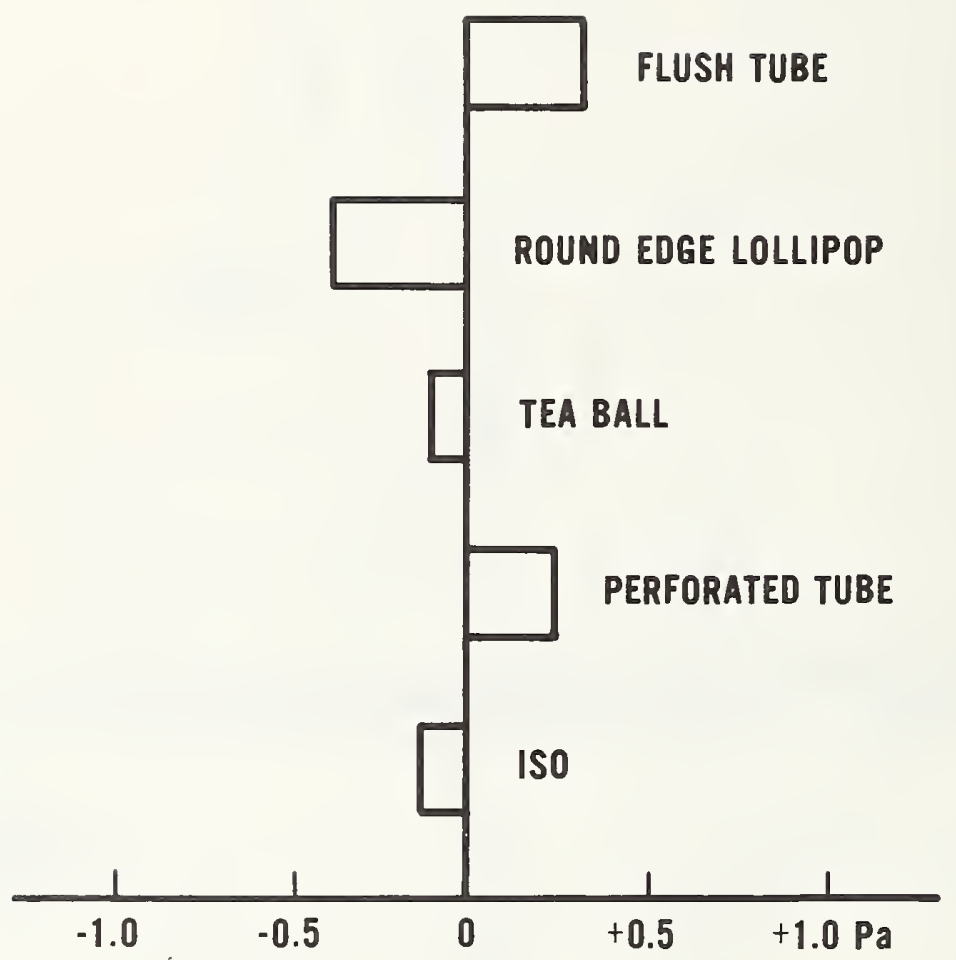

PROBE RESPONSE RELATIVE TO GROUP AVERAGE

Figure 7. Probe Response Relative to Group Average 
NBS-114A (REV. 2-8C)

U.S. DEPT. OF COMM

BIBLIOGRAPHIC DATA

SHEET (See instruction s)
1. PUBLICATION OR

REPORT NO.

NBSIR $81-2415$
2. Performing Organ. Report No

3. Publication Date

December 1981

4. TITLE AND SUBTITLE

Furnace Pressure Probe Investigation

\section{AUTHOR(S)}

James S. Steel

6. PERFORMING ORGANIZATION (If joint or other than NBS, see instructions)

7. Contract/Grant No.

NATIONAL BUREAU OF STANDARDS

DEPARTMENT OF COMMERCE

WASHINGTON, D.C. 20234

8. Type of Report \& Period Covered

9. SPONSORING ORGANIZATION NAME AND COMPLETE ADDRESS (Street, City, State, ZIP)

10. SUPPLEMENTARY NOTES

[.] Document describes a computer program; SF-185, FIPS Software Summary, is attached.

11. ABSTRACT (A 200-word or less factual summary of most significant information. If document includes a significant bibliography or literature survey, mention it here)

Several pressure probes of types used in fire endurance furnaces were tested at room temperature and compared in a furnace. It is suggested that total pressure be measured instead of static pressure and that the most accurate probe is a small flush hole in the specimen.

12. KEY WORDS (Six to twelve entries; alphabetical order; capitalize only proper names; and separate key words by semicolons)

Fire endurance; furnaces; pressure probes; static pressure

13. AVAILABILITY

XX Unlimited

$\square$ For Official Distribution. Do Not Release to NTIS

[ Order From Superintendent of Documents, U.S. Government Printing Office, Washington, D.C. 20402.

XX] Order From National Technical Information Service (NTIS), Springfield, VA. 2216I
14. NO. OF

PRINTED PAGES

28

15. Price 


